\section{Payback time for referee refusal}

Through my current and past work as associate editor of several refereed journals, I have discovered a negative correlation between the number of papers that a scientist publishes per year and the number of times that that scientist is willing to accept manuscripts for review. In other words, the biggest consumers of peer review seem to contribute the least to the process.

There are two solutions to this situation. We could abolish peer review altogether, which would be tantamount to doing away with science as we know it. Alternatively, we can apply a wellknown sociological principle, according to which no voluntary association can survive without incentives to increase compliance with its rules and penalties for disobedience. I therefore suggest that journals should ask senior authors to provide evidence of their contribution to peer review as a condition for considering their manuscripts. Such evidence should be easily verifiable in this age of data mining.

So, if you publish $10-20$ research papers a year with the help of 30-60 referees, do your bit in return.

Dan Graur University of

Houston, Texas, USA.

dgraur@uh.edu

\section{Fraud is not the big problem}

Whistle-blowers risk a huge personal backlash in exposing scientific misconduct (see, for example, D. Soeken Nature 505, 26 ; 2014), but they can hope to correct only a tiny percentage of the published literature.

Since 1980, when MEDLINE started categorizing retractions, there have been 6,119 retracted papers, amounting to $0.03 \%$ of the 17.8 million published. Even if the majority of these retractions arise from misconduct (see, for example, F. C. Fang et al. Proc.
Natl Acad. Sci. USA

http://doi.org/jf5; 2012), this still affects only a very small proportion of the literature overall.

From alarming estimates derived from studies by Bayer (F. Prinz et al. Nature Rev. Drug Discov. 10, 712; 2011) and Amgen (C. G. Begley and L. M. Ellis Nature 483, 531-533; 2012) that some $60-70 \%$ of biomedical research papers may contain irreproducible results, it would seem that our time would be better spent investigating experimental irreproducibility rather than hunting down fraudsters.

William Gunn Mendeley and the Reproducibility Initiative, California, USA. william.gunn@mendeley.com

\section{Resolving soil pollution in China}

On 30 December 2013, China's Ministry of Land and Resources reported that the country has 3.33 million hectares of farmland that are too contaminated to use. Given that this amounts to $2.5 \%$ of total arable land in China, more clarification is needed on the nature, extent, location and degree of soil contamination.

China is planning to invest

billions of dollars in soil

remediation in the coming years. But first the Chinese government should release detailed soilpollution data so that the problem can be better understood and the sources of contamination brought under control by legislation. For example, regulations should be put in place with regard to the dumping of sewage and industrial wastewater in rivers or on cultivated land, and then strictly enforced.

The government also needs to make clear who is expected to supervise soil remediation and management, and when and how polluted land can be decontaminated under current laws.

Ruishan Chen Hohai University,
Nanjing, China.

Chao Ye Nanjing Normal

University, China.

yeover@163.com

\section{Weighing up reuse of Soviet croplands}

There is a pressing need to evaluate the trade-offs on abandoned Soviet croplands between food production, the provision of ecosystem services and biodiversity conservation (see Nature 504, 342; 2013). Kazakhstan should be included in these assessments because, along with Russia, it commands some of the largest agricultural land reserves worldwide.

Trends in recultivation vary across the former Soviet Union. Reclamation in western Russia is only just starting, whereas Kazakhstan has reclaimed more than half of its abandoned cropland since 2000 .

This intensified agricultural production is good for rural development and poverty alleviation (see M. Petrick et al. World Dev. 43, 164-179; 2013). The implications for ecosystem services and biodiversity are less clear, however. Evidence is growing for biodiversity recovery (see, for example, J. Kamp et al. Biol. Conserv. 144, 2607-2614; 2011) and for increased carbon sequestration on land depleted by intensive agriculture across the former Soviet Union.

Johannes Kamp University of Münster, Germany.

johannes.kamp@uni-muenster.de

\section{Natural killers take on cancer}

Your Outlook supplement on cancer immunotherapy (Nature 504, S1-S17; 2013) focuses mainly on T cells as a promising immunotherapy tool. But natural killer (NK) cells, another type of immune cell, may also be suitable for treatment of some cancers and are currently being tested in clinical trials (see, for example, A. M. James et al. Front. Immunol. 4, 481; 2013, and M. Cheng et al. Cell. Mol. Immunol. 10, 230-252; 2013).

Unlike T cells, NK cells are not directly antigen-specific. However, they can use an antibody-dependent mechanism to kill tumour cells: the antigenspecific fragment of these antibodies recognizes molecules on the tumour-cell surface, which activates the NK-cell cytolytic machinery.

Another approach is to use antibodies that suppress the tumour-induced inhibition of NK cells. Also, anti-cancer agents such as lenalidomide act in part by modulating NK-cell function. Jacques Zimmer Public Research Centre for Health, Luxembourg. jacques.zimmer@crp-sante.lu

\section{EDITOR'S NOTE}

Nature has a strong history of supporting women in science and of reflecting the views of the community in our pages, including Correspondence. Our Correspondence pages do not reflect the views of the journal or its editors; they reflect the views only of the correspondents.

We do not endorse the views expressed in the Correspondence 'Publish on the basis of quality, not gender' (Nature 505, 291; 2014) - or indeed any Correspondences unless we explicitly say so. On re-examining this letter and the process, we consider that it adds no value to the discussion and unnecessarily inflames it, that it did not receive adequate editorial attention, and that we should not have published it, for which we apologize.

Nature's own positive views and engagement in the issues concerning women in science are represented by our special from 2013: www.nature.com/ women.

Philip Campbell, Editor-in-Chief, Nature 